\title{
Effects of Surface Alloying and Laser Beam Treatment on the Microstructure and Wear Behaviour of Surfaces Modified Using Submerged Metal Arc Welding
}

\author{
Regita BENDIKIENE *, Edmundas PUPELIS, Lina KAVALIAUSKIENE \\ Department of Manufacturing Engineering, Kaunas University of Technology, Studentu str. 56, 51424 Kaunas \\ cross $^{\text {ref }}$ http://dx.doi.org/10.5755/j01.ms.22.1.7621
}

Received 17 July 2014; accepted 25 January 2015

\begin{abstract}
In this study, the effects of surface alloying of cheap plain carbon steel using submerged metal arc technique and subsequent laser beam treatment on the microstructure and wear behaviour of surfaced layers were studied. This method is the cheapest one to obtain high alloyed coatings, because there is no need to apply complex technologies of powder making (metal powder is spread on the surface of base metal or inserted into the flux), it is enough to grind, granulate and blend additional materials. On the other hand, strengthening of superficial layers of alloys by thermal laser radiation is one of the applications of laser. Surface is strengthened by concentrated laser beam focused into teeny area (from section of $\mathrm{mm}$ till some $\mathrm{mm}$ ). Teeny area of metal heat up rapidly and when heat is drain to the inner metal layers giving strengthening effect. Steel surface during this treatment exceeds critical temperatures, if there is a need to strengthen deeper portions of the base metal it is possible even to fuse superficial layer. The results presented in this paper are based on micro-structural and micro-chemical analyses of the surfaced and laser beam treated surfaces and are supported by analyses of the hardness, the wear resistance and resultant microstructures. Due to the usage of waste raw materials a significant improvement $(\sim 30 \%)$ in wear resistance was achieved. The maximum achieved hardness of surfaced layer was $62 \mathrm{HRC}$, it can be compared with high alloyed conventional steel grade. Wear properties of overlays with additional laser beam treatment showed that weight loss of these layers was $~ 10 \%$ lower compared with overlays after welding; consequently, it is possible to replace high alloyed conventional steel grades forming new surfaces or restoring worn machine elements and tools.

Keywords: strengthening, surfacing, laser beam treatment, wear resistance.
\end{abstract}

\section{INTRODUCTON}

The service time of worn machine elements and their essential parts can be successfully prolonged by regular maintenance and well-timed repair of trouble surfaces. In previous works it has been demonstrated that with the systematic control of tool geometry the expenses of whole manufacturing process can be considerably reduced. It is a very economical practice to manufacture certain parts from low-cost, tough structural steel on which a layer of wearresistant alloy has been surfaced [1]. In such a case the volume fraction of the surfaced layer is usually much lower than $10 \%$ of the total volume of the tool or the machine element.

Wear of the machine elements and tools is progressive loss of material from the surface due to mechanical action with another solid body with or without abrasive particles or other medium [2]. Protection against such a surface damage is usually achieved through the modification of chemical composition and microstructure of superficies regions. Consequently, wear mitigation is at the core of many resource-based industries, which rely heavily on wear resistant materials [3].

Modification of chemical composition can be achieved by traditional methods using complex technologies of alloying or using welding processes for obtaining of wear resistant overlays on a bulk. Several welding techniques such as oxyacetylene gas welding (OAW), gas metal arc

\footnotetext{
${ }^{*}$ Corresponding author. Tel.: +370-37-323769.

E-mail address: regita.bendikiene@ktu.lt (R. Bendikiene)
}

welding (GMAW), shielded metal arc welding (SMAW) and submerged arc welding (SAW) can be used for overlay welding $[4,5]$. SAW is an attractive process for the manufacturing of overlays because of its productivity and high deposition rate. Conventional SAW flux is used to help protect the weld pool from the atmosphere [3]. Different types of supplied metal-powder addition to the welding area can be implemented in the overlaying practises: not alloying flux with solid alloyed wire (band); not alloying flux with powder wire (band); alloying flux (ceramic) with low carbon solid wire; alloying flux (ceramic) with alloyed wire (solid or powder) [6]. Over than 40 materials are used for overlay welding more or less effectively. The most common materials systems used in weld-deposited wear resistant overlays are the $\mathrm{Ni}-\mathrm{WC}$, $\mathrm{Cr}_{n} \mathrm{C}_{\mathrm{n}}$ [3], Cr-Mn, Cr-B, Cr-Ni, Cr-W-V systems; carbon presents in all wear resistance alloys. These materials, according abrasive working conditions are divided into the five categories: for usage under the conditions without dynamic load; under light dynamic load; under high dynamic load; under huge dynamic load, and under conditions of hydro-abrasive wear.

Combination of metal-powder addition gives as variety of results useful in the industry. Surfacing of worn machine elements and tools using industrial waste as metal powder in the flux for submerged arc welding, can solve every day growing waste utilization problem.

Alloys with good wear resistance and hardness are usually very expensive, but industrial applications still require such properties. Laser surface processing has been used as cost-effective technique to improve the surface 
properties of materials, by use of the laser beam heat for modification of its structure and physical characteristics [7]. Processes, which use only the generated heat, such as hardening and melting, and processes which use slurry [2], filler material for alloying and cladding are widely used to reach desired properties. The main feature of laser treated material is the increased hardness and wear properties compared to the submerged arc welded material [8].

Therefore, this paper focuses on the research of metal arc welding-based and afterwards laser beam treated without using additional materials overlays. Laser surface processing has traditionally been used to produce hard, wear and corrosion resistant surface on the bulk metal [9].

\section{EXPERIMENTAL DETAILS}

The base material for surfacing was cheap plain carbon steel provided as an $8 \mathrm{~mm}$ thick plate. The surfacing process was performed in a single pass using SMAW with alloying flux prepared from industrial waste materials and other additives. The chemical composition of alloying flux is presented in the Table 1. Content of blended metal powder additives in the ceramic flux cannot exceed $20 \%$ of whole mixture, the higher content can initiate the reduction of flux technological properties, especially separation of slag skin from the overlaid metal, also micro and macro discontinuity can arise.

Table 1. Chemical composition of alloying flux (mass \%)

\begin{tabular}{l|c|c|c|c|c|c|c|c|c|}
\hline No. & Glass & $\mathrm{W}$ & $\begin{array}{c}\mathrm{Fe}- \\
70 \% \mathrm{Mn}\end{array}$ & $\begin{array}{c}\text { Stainless } \\
\text { steel }\end{array}$ & $\mathrm{SiC}$ & $\mathrm{HS6}-5-2$ & K30 & $\begin{array}{c}\text { ciquid } \\
\text { glass }\end{array}$ \\
\hline $1^{*}$ & 28 & 34 & 12 & - & - & - & - & 10 \\
\hline 2 & 9 & - & - & 26 & 18 & 26 & 9 & 12 \\
\hline 3 & - & - & 8.5 & - & 17 & 66 & - & 8.5 \\
\hline 4 & 27.5 & - & - & 38 & 17 & - & 10.5 & 7 \\
\hline
\end{tabular}

When grinding waste raw materials (emery wheels, hard metal plates, glass and others) powders of different fraction were obtained, therefore the surfaced layer possessed structural and chemical discontinuity. To eliminate this effect, the prepared metal powder was blended with liquid glass, afterwards heated and held at the temperature of $250{ }^{\circ} \mathrm{C}$ for 3 hours and finally grinded.

In each case a single $1.2 \mathrm{~mm}$ diameter electrode low carbon wire was used for the welding $(\mathrm{C}<0.1 \%$; $\mathrm{Si}<0.03 \%, \mathrm{Mn} 0.35-0.6 \%, \mathrm{Cr}<0.15 \%, \mathrm{Ni}<0.3 \%)$. The submerged arc welding was carried out with an automatic welding device (torch MIG/MAG EN 500 78), using correctly chosen welding parameters: welding current $180-200 \mathrm{~A}$, voltage $22-24 \mathrm{~V}$, travel speed $-14.4 \mathrm{~m} / \mathrm{h}$, and the wire feed rate $-25.2 \mathrm{~m} / \mathrm{h}$. The prepared and blended metal powder was spread on the surface of the base metal and fused by metal arc. No additional flux was used, because prepared blended metal powder mixtures served us alloying and shielding flux.

Samples for the optical microstructural analysis were prepared by grinding, polishing to a near mirror finish and etching using $3 \%$ Nital solution; subsequently metallographic analysis was performed by the conventional metallographic techniques: MLA 10 and Carl Zeis Axio Scope A1 with the magnification of $100-350$.

Phase evolution and composition of surfaced layers was indicated by X-ray diffraction (XRD) [2] analysis conducted on DRON-6 using $\mathrm{Cu}-K_{\alpha}$ (monochrome graphite, diffraction plane $d_{(002)}=0.3352 \mathrm{~nm}$ ) radiation.

Chemical composition of overlaid superficies layers was analysed using qualitative and quantitative energy dispersive microanalysis on the Bruker AXS Microanalysis GmbH QUANTAX EDS system.

Mechanical behaviour of surfaced layers was assessed in the terms of hardness and wear properties. Hardness measurements of the layers were accomplished on the wrought and heat treated (tempered) surfaces using Rockwell tester TK -2 at the load of $1470 \mathrm{~N}$ with diamond indenter.

Wear resistance tests were performed and results of all the obtained surfaces were compared with conventional standard steel grade by weight loss of samples (with an accuracy of $\pm 0.1 \mathrm{mg}$ ).

Laser micro-spectrum analyser MLA10 equipped with Rubin Laser beam (wavelength $694.3 \mathrm{~nm}$ ) was used for the point strengthening of surfaced layers using secondary inflect tape, with diameter of aperture $90 \mu \mathrm{m}$ and plan chromatic objective lens $16 \mathrm{x} / 0.2 \infty / 0$.

\section{RESULTS AND DISCUSSION}

Chemical composition of surfaced layers revealed after EDS analysis had showed high concentration of alloying elements in the superficies layers (see Table 2).

Table 2. Chemical composition of surfaced layers

\begin{tabular}{|c|c|c|c|c|c|c|c|c|c|c|}
\hline \multirow[b]{2}{*}{ No. } & \multicolumn{10}{|c|}{ Content of elements in mass $\%$} \\
\hline & $\mathrm{C}$ & $\mathrm{Si}$ & $\mathrm{Mn}$ & $\mathrm{Cr}$ & W & $\mathrm{Ni}$ & $\mathrm{V}$ & Mo & Co & $\mathrm{Fe}$ \\
\hline 1 & 2.11 & 1.28 & 2.49 & 0.21 & 7.59 & - & - & - & - & \\
\hline 2 & 1.75 & 2.36 & 1.12 & 1.57 & 2.58 & 0.6 & 0.29 & 0.58 & 0.51 & $\infty$ \\
\hline 3 & 2.18 & 2.24 & 2.97 & 1.41 & 1.42 & - & 0.37 & 0.31 & - & $\Xi$ \\
\hline 4 & 2.12 & 2.44 & 0.89 & 0.95 & 2.64 & 0.64 & 0.06 & 0.21 & 0.57 & \\
\hline
\end{tabular}

Maximum depth of the surfaced layer was $3 \mathrm{~mm}$, all the volume of the weld showed presence of alloying elements, the highest content obviously was found in the superficies layers and the lowest near to the parent metal.

The obtained chemical compositions have shown that it is possible to reach high concentration of alloying elements in the surface layer using waste raw materials; accordingly, there is no need to use comparatively expensive industrial alloying elements.

XRD results confirmed the presence of retained austenite in the layers 1, 2 and 3, peaks $\gamma(111)$ and $\gamma(200)$ in Fig. 1.

After subsequent tempering at the temperature of $550{ }^{\circ} \mathrm{C}$ retained austenite transformed to the martensite, hardness of the layers was slightly increased (see Table 3) and higher peak (comparing with not tempered layer) of martensite was observed in the XRD patterns, see Fig. 2.

Tested overlays were subjected to two cycles of tempering at the same temperature, and additional high temperature tempering at $600{ }^{\circ} \mathrm{C}$. No presence of retained austenite was observed in the XRD pattern of layer No. 4 as on cooling after surfacing this layer hardened during 
austenite transformation into the martensite.

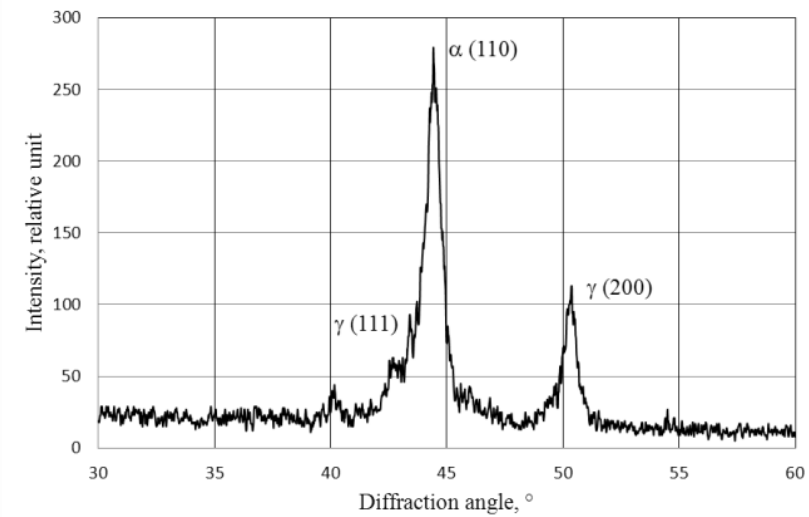

Fig. 1. XRD of layer No. 3 before tempering. Quantity of retained austenite $19.9 \%$

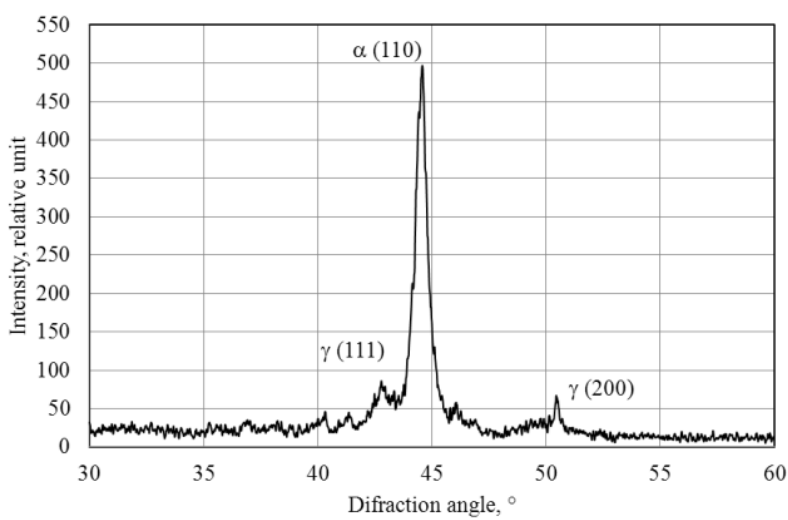

Fig. 2. XRD of layer No. 3 after tempering. Quantity of retained austenite $12.0 \%$

Table 3. Influence of tempering temperature on the hardness (HRC) of surfaced layers

\begin{tabular}{|c|c|c|c|c|}
\hline Layer No. & $\begin{array}{c}\text { Without } \\
\text { tempering }\end{array}$ & $\begin{array}{c}\text { Tempered } \\
\text { at } 550{ }^{\circ} \mathrm{C} \\
\text { (I cycle) }\end{array}$ & $\begin{array}{c}\text { Tempered } \\
\text { at 550 }{ }^{\circ} \mathrm{C} \\
\text { (II cycle) }\end{array}$ & $\begin{array}{c}\text { Tempered } \\
\text { at } 600{ }^{\circ} \mathrm{C}\end{array}$ \\
\hline 1 & 57 & 58 & 59 & 57 \\
\hline 2 & 58 & 60 & 59 & 55 \\
\hline 3 & 62 & 63 & 62 & 61 \\
\hline 4 & 58 & 56 & 55 & 52 \\
\hline
\end{tabular}

Before wear test, all the samples of surfaced layers were cleaned and then weighed on an electronic balance $( \pm 0.1 \mathrm{mg}$ ) [4]. Abrasive wear tests were conducted on surfaced layers and on the conventional standard steel grade (C 0.9-1.05\%, Si 0.10-0.40\%, Mn 0.80-1.10\%, Cr $0.90-1.20 \%$, W $1.20-1.60 \%$ ) sample using a rough emery paper with aluminium oxide (GOST 6456-7, 14A8HM 446) as the abrasive substrate. Prepared wear samples $(6 \times 20 \mathrm{~mm})$ were pressed to the counterpart material under the load of $5 \mathrm{~N}$, total wear test time was $10 \mathrm{~min}$ when constant sliding distance was $5.03 \mathrm{~m}$. After wear tests all the samples were weighed; results are presented in Fig. 3.

Obtained results confirmed presumptions of proper selection of chemical compounds and waste raw materials for preparation of blended alloying flux; weight loss of the surfaced layers was lower than the wear of standard steel grade sample. Therefore, such a technology of surfacing and suggested blended metal powder mixtures might be successfully used for the formation of high alloyed thin overlays on the surface of cheap plain carbon steels or for the renovation and restoration of worn machine elements and tools [1].

Fig. 4 presents the cross-sectional view of the layer No. 3, which during wear test showed the best results.

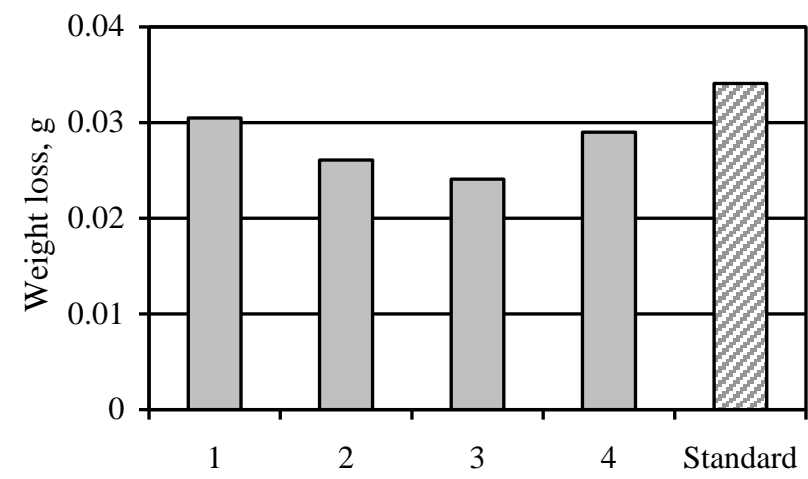

Fig. 3. Results of wear test. Numbers indicate surfaced layers (Table 2)

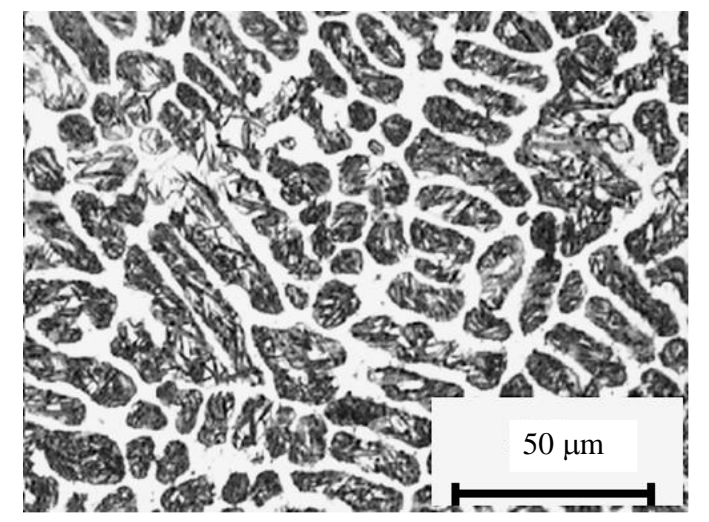

Fig. 4. Sample structure of surfaced layer

It is evident that microstructure of superficies layer No. 3 consists of the ledeburite eutectic [10]. Precipitation of chromium carbide (EDS analysis) in the structure of layer No. 3 enabled to reach maximum hardness (63 HRC) and the lowest rate of wear.

Another way to improve wear properties of different steel surfaces is laser surface engineering [7, 11]. Laser surface engineering encompasses several applications that are mainly related to the surface properties such as hardness and resistance to wear. Laser surface engineering methods can be broadly classified into the 2 categories [7]: thermal process; treatment without changing of surface composition (no material addition) and thermo-chemical process; treatment with change in composition (material addition). These processes are flexible and it is possible to treat small surface areas, leaving the other parts unaffected.

This study concentrates on the first type of laser surface engineering. Under the very concentrated laser irradiation, applied to the tiny area, temperature of the metal was increased above the critical temperatures (austenitic) sometimes even till the fusion and by heat conduction to the parent metal, a thin surface layer was fast cooled down by self quenching. Laser beam treatment is mostly used for the materials which can not be hardened during heat treatment, ex., stainless steel, titanium and others. Similarly, this treatment is applied for tool steels, 
because during surfacing uniform fine grained structure is formed, wear and fatigue resistance are increased.

The surfaced layers were laser beam treated in order to evaluate influence of laser irradiation on the wear properties and microstructure of the layers. Such a point laser treatment pattern was suggested for this test: distance between parallel tracks $\sim 200 \mu \mathrm{m}$, distance between the centres of laser effected zones in the tracks $\sim 300 \mu \mathrm{m}$, the diameter of laser effected zone was $\sim 180 \mu \mathrm{m}$ (the pattern is shown in the Fig. 5).

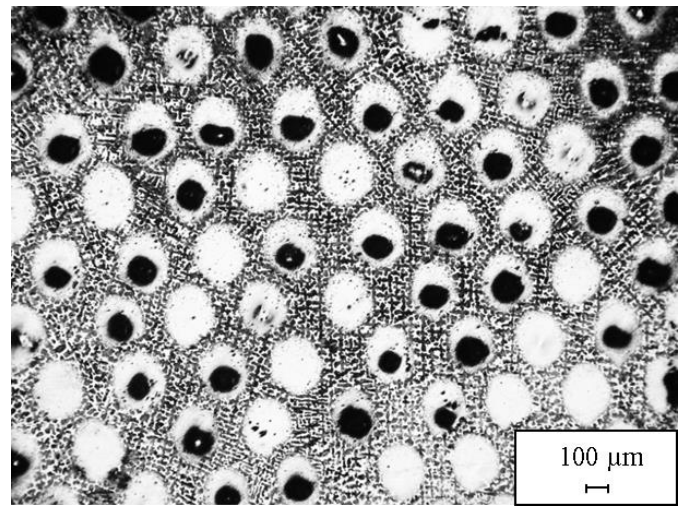

Fig. 5. Pattern of laser treatment

The pulses of laser irradiation as highly concentrated energy recourse heated up tiny volumes of the metal at high velocity. Laser assisted metal melt was partially flushed out of the laser effected zone, as a result pits were formed on the surface layer. Rapid cooling initiated hardening of metal portions alongside the pits, and the white areas, which were revealed after etching with $3 \%$ Nital solution, were formed (see Fig. 3). Geometrical parameters of the affected and strengthened zones can be changed: depth of pits $1-700 \mu \mathrm{m}$, diameter of pits $10-2000 \mu \mathrm{m}$.

Because of an irregularity of surfaced structure and the oscillations of irradiation power, in some cases the metal portions were flushed out slighter than in others, so under this circumstance the lesser pits were composed.

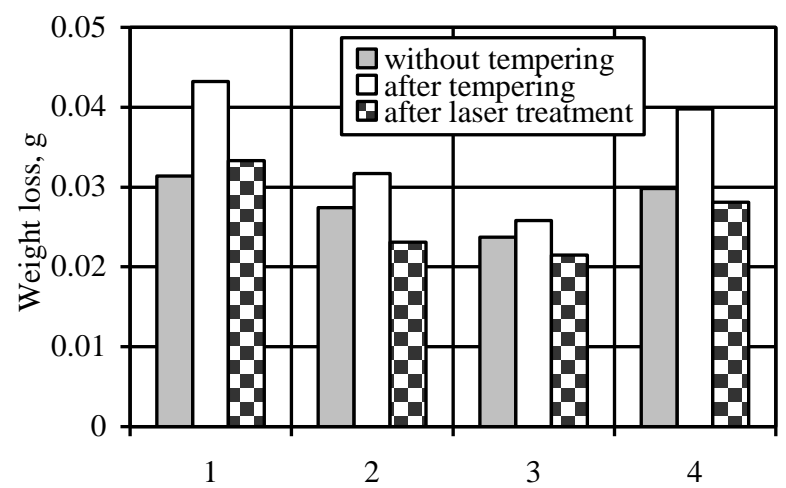

Fig. 6. Wear of sample layers. Numbers indicate surfaced layers (Table 2)

Thereinafter all the surfaced and laser treated samples were tempered at the temperature of $550{ }^{\circ} \mathrm{C}$. On the wear test prepared samples with the cross sectional area of $36 \mathrm{~mm}^{2}(6 \times 6 \mathrm{~mm})$ were pressed to the rough emery paper under the load of $1.5 \mathrm{~N}$; total wear test time was $10 \mathrm{~min}$. The results of wear test are presented in Fig. 6.
Weight loss of laser treated layers was lower compared with the wear of tempered layers, but approximately the same compared with not tempered layers [8]. It is evident that it is not necessary to apply tempering after laser treatment.

Initially laser treated surface layers were rugged enough (Fig. 5), and during wear test hard particles alongside the pits penetrated to the deeper volumes of the samples initiating destruction of surface; different results were obtained on the surfaces without pits. Elongated wear test (55 min) was accomplished seeking to abrade all the laser treated volume of the sample (see Fig. 7).

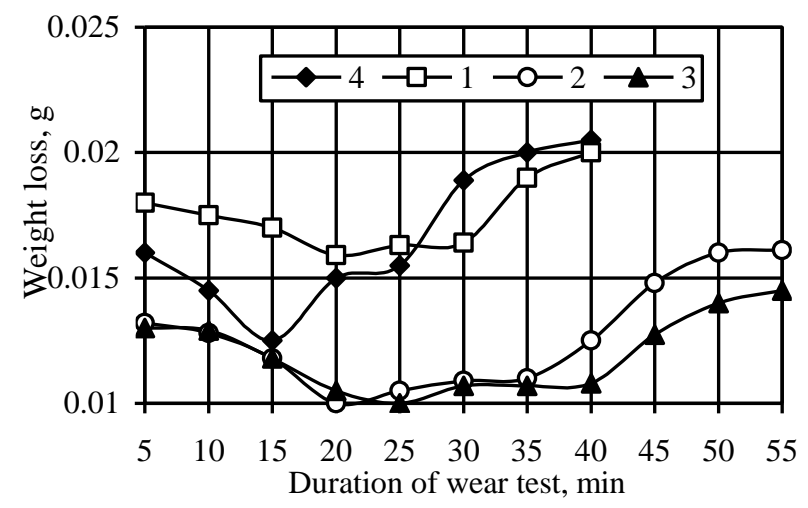

Fig. 7. Wear test duration dependence on weight loss of samples. Numbers indicate surfaced layers (Table 2)

\section{CONCLUSIONS}

Surfacing of plain carbon steel using automatic submerged arc welding with alloying flux was carried out to achieve high alloyed layers with increased hardness and better wear resistance. Afterwards, these layers were subjected to laser beam treatment and results were compared with the wear results obtained on surfaced layers. The following conclusions can be made:

1. It has been shown the ability of submerged arc welding and laser technology to improve the surface wear properties. It is possible to use suggested layers for the formation of high alloyed overlays on the surface of cheap plain carbon steel and the restoration of worn machine elements and tools.

2. A significant improvement in wear resistance was achieved due to the usage of waste raw materials us an alloying flux for the submerged metal arc technology. The maximum achieved hardness $62 \mathrm{HRC}$ can be compared with high alloyed conventional steel grade.

3. When using powder of glass and SiC powder there is no need to use conventional flux for submerged arc welding. Silicon served as the deoxidiser, and the composed liquid slag prevented weld pool from the surrounding; metal arc was homogeneous and quality of formed metal overlays was high. Using such a combination of glass and $\mathrm{SiC}(50 \%$ and $50 \%)$, hardness of 67 HRC was achieved.

4. Wear properties of overlays with additional laser beam treatment showed that weight loss of these layers was $\sim 10 \%$ lower compared with overlays after welding. 


\section{REFERENCES}

1. Grum, J., Slabe, J.-M. A Comparison of Tool-Repair Methods Using $\mathrm{CO}_{2}$ Laser Surfacing and Arc Surfacing Applied Surface Science 208-209 2003: pp. 424-431.

2. Basu, A., Samant, A.N., Harimkar, S.P. Duta Majumdar, J., Manna, I., Dahotre, N.B. Laser Surface Coating of Fe-Cr-Mo-Y-B-C Bulk Metallic Glass Composition on AISI 4140 Steel Surface \& Coatings Technology 202 2008: pp. 2623-2631.

3. Mendez, P.F., Barnes, N., Bell, K., Borle, S.D., Gajapathi, S.S., $\quad$ Guest, S.D., $\quad$ Izadi, H., Gol, A.K., Wood, G. Welding Processes for Wear Resistant Overlays Journal of Manufacturing Processes 16 2014: pp. 4-25. http://dx.doi.org/10.1016/j.jmapro.2013.06.011

4. Arabi Jeshvaghani, R., Harati, E., Shamanian, M. Effects of Surface Alloying on Microstructure and Wear Behaviour of Ductile Iron Surface-Modified with a Nickel-based Alloy Using Shielded Metal Arc Welding Materials and Design 32 2011: pp. $1531-1536$.

5. Tušek, J., Suban, M. High-Productivity Multiple-Wire Submerged-Arc Welding and Cladding with Metal-Powder Addition Journal of Materials Processing Technology 133 2003: pp. $207-213$.
http://dx.doi.org/10.1016/S0924-0136(02)00235-2

6. Ambroza, P.A., Kavaliauskiene, L., Pupelis, E. Automatic Arc Welding and Overlaying Welding of Steel Using Waste Materials Powder Mechanics 2 (82) 2010: pp. 75-79.

7. Montealegre, M.A., Castro, G., Rey, P., Arias, J.L., Vázquez, P., González, M. Surface Treatments by Laser Technology Contemporary Materials I (1) 2010: pp. 19-30.

8. McPherson, N.A., Chi, K., Baker, T.N. Submerged arc welding of stainless steel and the challenge from the laser welding process Journal of Materials Processing Technology 134 2003: pp. 174-179. http://dx.doi.org/10.1016/S0924-0136(02)00466-1

9. Duta Majumdar, J. Laser Assisted Composite Surfacing of Materials for Improved Wear Resistance Physics Procedia 5 2010: pp. 425-430.

10. Trepczyńska-Lent, M. Solidification of Ledeburite Eutectic Archives of Foundry Engineering 12 (2) 2012: pp. 71-74.

11. Steen, W.-M. Laser Material Processing. Springer, 2010: p. 558.

http://dx.doi.org/10.1007/978-1-84996-062-5 